\title{
Report of the 21st European Stroke Conference, Lisbon, May 22-25, 2012
}

\author{
J.P. Mohr \\ Neurological Institute, Columbia University College of Physicians and Surgeons, New York, N.Y., USA
}

It has been 11 years since the last European Stroke Conference was held in this city, its host Dr. José M. Ferro. By review of the conference history, some 600 attended the first conference, held in Düsseldorf, the numbers having grown by a factor of 5 to this year's 3,272 . The program continues to expand its scope, attracting $>1,500$ abstracts ( $90 \%$ of them of a quality to be accepted), 129 of which concerned the subject of acute stroke, and 62 qualified as large clinical trials. The UK continues to lead individual countries by submissions, followed by Germany, Spain, Portugal this year hosting ahead of France, followed by South Korea.

Two full sessions were needed to review the largest of the ongoing clinical trials. Likewise, two poster sessions were needed, including an innovation for four sets shown in electronic form. The number of symposia has also increased, now three educational and 13 scientific. The popular 1-day session for nurses and allied health professionals continues on the first day of the conference, as well as 10 teaching courses attended by 1,146 people.

Advances in web functions allow some who could not attend to seek out the general content on the conference website at http://www.esc-archive.eu/lisbon2012/lis_ 2012.html

This year the Johann Jacob Wepfer award was given to Dr. Louis R. Caplan (Boston), who reviewed his extensive experience with vertebrobasilar disease. Young investigator awards were given to D.P.J. Howard (UK), M. Mazya (Sweden), A.H. Witt (Denmark), J. Pennlert (Sweden), and C. Rosso (France) for studies using data from large clinical trials and registries. J. Agulla (Spain), A. Charidimou (UK), H.B. Browers (USA), A.S.E. Bor (The Netherlands) and M. Duering (Germany) were awarded for innovative studies from their own research institutions. ESO awards were given to G. Turc (France), K.J. Frontzek (Switzerland) and C.L. Seifert (Germany).

The opening day for the European Stroke Conference featured as part one the large clinical trial session chaired by D. Toni (Rome) and J.P. Mohr (New York) held a large auditorium to an overflow audience; the second part was presented on Friday with brand-new results from six trials.

Martin M. Brown (London) presented the late outcome for carotid artery angioplasty (CAS) versus carotid endarterectomy (CAE). Although the initial 30-day rates, well known from prior presentations, favored CAE, the late outcomes (after 30 days) were less striking, nonetheless they showed a hazard ratio of 1.98 still favoring CAE for any stroke, fatal stroke and death events; myocardial infarction was slightly more frequent in the CAE group compared with CAS, findings similar to that of the American CREST study. He cited - but no explanation has yet been found for - the slightly higher stroke events in the territory contralateral to that undergoing CAS.

M.G. Lansberg discussed the recent results of the DEFUSE 2 trial, this being one of several attempting to show the degree to which inferred territory at risk could be identified. The expectation is that this region could

\begin{tabular}{ll}
\hline KARGER & (c) 2013 S. Karger AG, Basel \\
1015-9770/13/0351-0005\$38.00/0 \\
$\begin{array}{l}\text { Fax +41 61 306 } 1234 \\
\begin{array}{l}\text { E-Mail karger@karger.com } \\
\text { www.karger.com }\end{array}\end{array}$ & $\begin{array}{l}\text { Accessible online at: } \\
\text { www.karger.com/ced }\end{array}$
\end{tabular}

Prof. Jay P. Mohr

Neurological Institute, Columbia University College of Physicians and Surgeons 710 West 168th Street

New York, NY 10029 (USA)

E-Mail jpm10@columbia.edu 
show favorable clinical and imaging response from successful recanalization in the occluded territory. Infarcts affecting the deep and superficial middle cerebral territories were those most cited. Advances in fully automated computer programs for MR imaging have demonstrated their ability reliably to identify the perfusionweighted image territory distal to the diffusion-weighted image lesions. The studies were done at nine sites from 2009 to 2011, using patients whose NIH stroke score (NIHSS) was $>5$, who were imaged within $90 \mathrm{~min}$, with the diffusion-weighted image/perfusion-weighted image 'mismatch' documented. The imaging sequences were then repeated after intra-arterial effort at recanalization, and follow-up studies using FLAIR imaging done on day 5 . The hypothesis was confirmed, with reperfusion associated with reduced lesion growth as measured by diffusion-weighted imaging and certified by FLAIR on day 5.

Antonio Dávalos presented the results of the International Citicoline Trial on acUte Stroke (ICTUS study). Pooled data was reviewed. Citicoline was used to treat 873 of 2,298 patients with an acute ischemic stroke within $12 \mathrm{~h}$ of onset whose NIHSS was $>8$. Citicoline was given at a dose of 1,000 $\mathrm{mg}$ i.v. over $60 \mathrm{~min} \times 3$ days and thereafter at the same oral dose every $12 \mathrm{~h}$. The demographic features showed a good balance between the cohorts. Tissue plasminogen activator (tPA) was used for $43 \%$ of those analyzed.

The results showed no statistically significant difference versus placebo for the two groups for overall mortality, global outcome, and shift in a favorable direction for the NIHSS, modified Rankin Score, or Barthel Index. Subset analyses including subdivision of the NIHSS (segregating the moderate from the severe ranges) showed no differences, save for those aged $>70$, who showed some benefit. Citicoline use did not alter the risk of hemorrhagic conversion.

Peter Sandercock presented the results of the third International Stroke Trial (IST3) of acute ischemic stroke of 3,035 patients treated in 156 participating hospitals in 12 countries using tPA during the period up to $6 \mathrm{~h}$ from clinical onset of stroke. The criteria for inclusion were extremely clear: those deemed eligible for tPA within the usual time frame of $0-3 \mathrm{~h}$ from onset were given tPA; those deemed unsuitable for any reason did not; if the use of tPA was considered promising but beyond the 3-hour time period up to $6 \mathrm{~h}$, the patient was eligible and could be randomized for tPA use versus placebo.

Imaging was done by either CT or MRI. Patients were monitored for blood pressure for $24 \mathrm{~h}$, followed by repeat
CT or MRI at $24 \mathrm{~h}$, adjudicated for events or death $<7$ days. The outcome was assessed by the Oxford Handicap Scale (OHS) for those alive and independent (OHS 0-2) in follow-up.

Among the notable findings were the expected best results for those treated in the 0 - to 3 -hour window. No differences were found in subgroup analyses for baseline NIHSS across the range of time treated. There was more frequent intracerebral hemorrhage within 7 days (104 tPA-treated vs. 16 controls, OR 6.94); more frequent deaths in the 163 tPA-treated versus 107 placebo-treated patients within 7 days (OR 1.6, $\mathrm{p}=0.001$ ), but in the period thereafter up to 6 months 554 tPA-treated were alive versus 534 given placebo, an absolute difference favoring tPA of 14/1,000. Further, there was a favorable OHS shift value of $1.27(\mathrm{p}=0.001)$ and a particularly interesting observation that $53 \%$ of the cohort were age $>80$, and proportionately actually fared better than those younger. Formal publication appeared in The Lancet the same day as the presentation.

Joanna M. Wardlaw finished the session with an extensive meta-analysis of thrombolysis trials. Her review covered 12 trials and 7,012 patients treated with tPA within $6 \mathrm{~h}$ of stroke. As in IST3, its use increased the odds ratio of being alive and independent as measured by the modified Rankin Scale 0-2 (OR 1.17). As also seen in IST3, the biggest effect was for those treated within $3 \mathrm{~h}$ (OR 1.53). The early deaths were most often explained by symptomatic intracranial hemorrhage (affecting 272 with tPA vs. 63 for placebo, OR 3.72). The meta-analysis showed similar benefits for those over or under age 80. Like Dr. Sandercock's presentation, Dr. Wardlaw's material appeared in the same issue of The Lancet.

The multiple sessions now are all published in the ebook with references from all abstracts accepted and presented either as oral or poster presentations at http:// www.esc-archive.eu/lisbon 2012 /ebook12/index. $\mathrm{html} \# / 1$ / or as Cerebrovasc Dis 2012;33(suppl 2).

Well attended and sometimes crowded were educational symposia on Wednesday and Thursday as well as 13 scientific symposia on all 3 days of the European Stroke Conference. This is also true for four lunch symposia and eight satellite symposia, all sponsored and presented by companies active in stroke research.

The special lecture was given by S. Greenberg (USA) on the last day of the meeting: Intracranial Hemorrhage - an Update (see also Brouwers HB, Greenberg SM: Hematoma expansion following acute intracerebral hemorrhage. Cerebrovasc Dis 2013;35(in press)). 